\title{
SOCIOLOGIA NO ENSINO MÉDIO E O PIBID: BRINCANDO, PENSANDO E CONSTRUINDO PRÁTICAS EDUCATIVAS COM AUTONOMIA
}

\author{
Elisabete Cristina Cruvello da Silveira ${ }^{\mathrm{i}}$ \\ Natália Pereira ${ }^{\text {ii }}$ \\ Wallace Moura ${ }^{\text {iii }}$
}

\begin{abstract}
Resumo: $\mathrm{O}$ artigo tece reflexões sobre práticas educativas críticas no ensino de Sociologia no âmbito do PIBID. Conceitos como mediação didática e autonomia à luz dos aportes de Freire, Arroyo, Verhaege, Wolfs, Simon, Compère, Schwartz e Almeida serviram para captar as vivências realizadas na escola, bem como elabora-las conceitualmente. O uso de jogos didáticos e as vivências na semana da Consciência Negra representam os exemplos concretos das práticas educativas que criaram centros de interesse e chaves de leitura essenciais ao processo de transposição didática como prática epistemológica. Além disso, essas atividades assinalam a relevância do PIBID como campo concreto para elaborar novos dispositivos de aprendizagem e outras práticas educativas relevantes no ensino da Sociologia.
\end{abstract}

Palavras-chave: Práticas educativas críticas; Mediação didática; Sociologia no Ensino Médio; Autonomia; PIBID.

\section{SOCIOLOGÍA EN LA EDUCACIÓN SECUNDARIA Y EL PIBID: JUGANDO, PENSANDO Y CONSTRUYENDO PRÁCTICAS CON AUTONOMÍA EDUCATIVA}

Resumen: El artículo reflexiona sobre las prácticas educativas críticas en la enseñanza de la sociología en el ámbito del PIBID. Conceptos tales como mediación didáctica y autonomía a la luz de las contribuciones de Freire, Arroyo, Verhaege, Wolfs, Simon, Compère, Schwartz y Almeida sirven para capturar las experiencias llevadas a cabo en la escuela y su elaboración conceptual. El uso de juegos educativos y experiencias durante la semana de la Conciencia Negra representan ejemplos concretos de las prácticas educativas que han creado centros de claves de interés y la elaboración de conceptos esenciales para el proceso de transposición didáctica como una práctica epistemológica. Además, estas actividades indican la relevancia de PIBID como campo concreto para desarrollar nuevos dispositivos de aprendizaje y otras prácticas educativas relevantes en la enseñanza de la sociología.

Palabras-Clave: Prácticas educativas críticas; Mediación didáctica; Sociología en la Escuela Secundaria; Autonomía; PIBID 


\section{Introdução}

Nosso artigo tece reflexões a respeito das práticas educativas críticas desenvolvidas no âmbito do PIBID (Programa Institucional de Bolsas de Iniciação à Docência) para o ensino de Sociologia na educação básica. Em primeiro lugar, concebemos práticas educativas críticas como aquelas que fomentam a problematização dos conceitos-chave, bem como elaboram saberes escolares potencializadores da autonomia e do pensamento crítico no processo de ensino-aprendizagem. Duas indagações norteiam nossa discussão: De que maneira as aulas de Sociologia no ensino médio desenvolveram práticas educativas para formar sujeitos - alunos e docentes - com autonomia? Até que ponto o PIBID constitui um instrumento aglutinador de experiências, narrativas e saberes escolares críticos?

A literatura a respeito de práticas educativas críticas para o ensino de Sociologia vem se consolidando paulatinamente, favorecida com o retorno da Sociologia como disciplina obrigatória com a promulgação da Lei 11.684, de dois de junho de 2008. A intermitência da disciplina Sociologia no currículo do ensino médio, por vezes ausente, facultativa ou obrigatória engendrou uma incipiente produção de material didático e divulgação de pesquisas atinentes à temática do seu ensino na educação básica ${ }^{\mathrm{i}}$.

Além da obrigatoriedade da disciplina, o PIBID colabora neste processo paulatino de construção de práticas educativas críticas no ensino de sociologia, constituindo-se um aglutinador dessas experiências alternativas. Ações do subprojeto da Licenciatura de Ciências Sociais da UFF de Niterói visam à elaboração e uso de material didático capacitando profissionalmente os bolsistas na docência, bem como o aprofundamento nos estudos a respeito da mediação didática inovadora, voltando-se à produção de novos modos de concepções e de dispositivos de aprendizagem.

Um dos problemas recorrentes apontados na academia a respeito do ensino da sociologia diz respeito à dualidade entre a realidade da escola pública e as discussões teóricas na sala de aula da universidade, ou seja: a separação entre discurso acadêmico na formação de graduandos em licenciatura e o que se apresenta no ensino público. Distanciamento este que cobra mais a frente, quando os novos professores assumem suas turmas, com a limitação causada pela desigualdade estrutural da educação pública brasileira, desestimulando os novos licenciados, reverberando nas práticas escolares e em suas relações com os estudantes. Neste sentido, o PIBID como uma política de formação de novos professores possibilita reduzir a problemática 
do "choque de realidade" dos egressos da licenciatura que assumem logo a docência em Sociologia no Ensino Médio, como enfatizam Oliveira e Costa:

Neste contexto, muitos professores recém-formados e que estão ingressando nas escolas, descobrem que sua formação no ensino superior não significou uma formação específica para a docência, encontrando uma imensa dificuldade de realizar a transposição ou mediação didática. Nos debates e reflexões teóricas em didáticas é o que se denomina de 'choque de realidade'. (2013, p.120)

Levando em conta a problematização detalhada, nossa reflexão teórica se sustenta nas contribuições de Jean Claude Verhaege, José Luis Wolfs, Xavier Simon, Dominique Compère sobre a transposição didática como uma prática epistemológica. Assim também, analistas brasileiros sobre uma concepção de ensino crítico alimentaram nossa discussão, como Miguel Arroyo, Paulo Freire, Geraldo Almeida, Gilson Schwartz.

Frente à passividade da memorização dos conteúdos em sala de aula, o PIBID na escola em tela procura estimular o pensamento criativo dos jovens nas aulas de sociologia. Ao mesmo tempo em que eram apresentados os temas referentes ao currículo mínimo da disciplina, os estagiários do PIBID fomentavam discussões em grupos, apreensão de opiniões distintas, a elaboração de jogos que aparecem em grande medida em outros campos do conhecimento, como Biologia, Física, Matemática, mas escassos na Sociologia. Neste quesito os jogos propostos pelos bolsistas, sob a coordenação da UFF e da supervisora, geraram progressos não só numa apreciação por parte das turmas das aulas de Sociologia, como também ajudaram a expor os saberes invisibilizados dos alunos, estimulando o fazer-se enquanto sujeito como os saberes produzidos na Semana da Consciência Negra.

Nossa reflexão se estrutura em torno de dois tópicos. O primeiro discute as especificidades e complexidades da mediação didática no ensino de Sociologia, no sentido de salientar a relevância de formação de centros de interesse e da captação de chaves de leitura no processo de ensino-aprendizagem. O segundo, narrativas sobre diversas experiências realizadas no campo escolar no PIBID são detalhadas como as vivências com os jogos didáticos e a construção de saberes escolares na Semana da Consciência Negra. Por fim, as considerações finais tecem sínteses acerca das possibilidades e desafios das práticas educativas críticas no ensino da Sociologia no campo do PIBID. 
Mediação didática: Suas especificidades para elaborar práticas educativas críticas no ensino de Sociologia

De modo sintético, Geraldo Almeida coloca que o termo transposição didática foi introduzido por Michel Verret, em 1975, sendo apropriado e aprofundado por Yves Chevallard. Nesta reconstrução, Almeida afirma que este termo foi divulgado no âmbito brasileiro por Phillipe Perrenoud, concebendo a transposição como a essência do ensinar, ou seja, "a ação de fabricar artesanalmente os saberes, tornando-os ensináveis, exercitáveis e passíveis de avaliação no quadro de uma turma, de um ano, de um horário, de um sistema de comunicação e trabalho". (2007, p.9)

Esta essência de ensinar que envolve a construção de saberes foi compreendida por Verhaeghe, Simon, Wolfs e Compère como "praticar a Epistemologia v." Segundo esses analistas, "muito antes da escola, a teoria científica foi transformada, sofreu uma primeira transposição didática.” (2010, p.83). Estabelecendo um paralelo entre os cientistas e os professores no que diz respeito ao processo de transposição didática, explicam que a complexidade do papel docente é criar centros de interesse e chaves de leitura, como elucida a passagem à continuação de Verhaeghe, Simon, Wolfs e Compére:

Contrariamente ao que se poderia geralmente pensar, o problema dos cientistas que procuram fazer que suas hipóteses sejam aceitas e o do professor que ensina são muito próximos. O princípio é mostrar a utilidade de certas representações ou teorias, às vezes em substituição a concepções preexistentes, para explicar certos fenômenos.

Mas a tarefa do professor apresenta uma complexidade suplementar. O pesquisador dirige-se a uma comunidade que, a priori, compartilha os mesmos centros de interesse. Em uma sala de aula, é muito diferente. Os alunos não são a priori sensíveis aos problemas científicos: eles possuem centros de interesse diferentes dos interesses dos cientistas que construíram os saberes que se tentará ensinar. (...)

Em suma, o professor encontra-se diante de alunos que não possuem as mesmas chaves de leitura do mundo que aqueles que descobriram os saberes ensinados e para os quais a disciplina científica ou o capítulo estudado não apresentam um interesse maior. Para o professor é um desafio permanente conseguir passar uma mensagem em tal contexto! (2010, p. 85).

A diversidade de centros de interesse em uma turma de Ensino Médio de Sociologia com mais de quarenta alunos, bem como as distintas chaves de leitura que os alunos possuem, tornam a essência de ensinar uma tarefa árdua para os docentes experientes, e especialmente, os novatos. Neste sentido, cabe questionar: para que serve o ensino da Sociologia na educação 
básica? Os relatos apresentados e sustentados no presente artigo procuram responder essa questão que atravessa a transposição didática, evidenciando nossa concepção epistemológica a respeito do ensino da sociologia em uma escola pública no século XXI. Segundo Verhaeghe, Wolfs, Simon e Compère "todo ensino provém de uma concepção epistemológica, mesmo que implícita, e os professores não podem escapar, pelo menos em parte, à influência direta ou indireta dos instrumentos que eles utilizam". (2010, p.83)

Do nosso ponto de vista, o jogo didático como um dispositivo para pensar a Sociologia no Ensino Médio, fomenta o processo de ensino e aprendizagem, além de:

$\checkmark$ Ampliar a capacidade de abstração e outras operações lógicas, como elaboração e análise, superando uma aprendizagem voltada para uma simples memorização ou decoreba;

$\checkmark$ Possibilitar a prática de regras sociais de convivência como colaboração mútua, respeito e ética;

$\checkmark$ Gerar prazer em confronto ao acirramento da competição perversa entre os discentes. Assim também, o jogo não é neutro e nem uma mera técnica detendo uma concepção epistemológica acerca do mundo social. Gilson Schwartz problematizando os vínculos entre educação, videogames e moralidades pós-modernas propõe: “Em substituição ao 'Penso, logo existo' surge no horizonte outra perspectiva - 'Brinco, logo aprendo', pois o pensar não se resume a uma forma unívoca, determinada do existir." (2014, p.22) Na realidade, nossa escola encontra-se fundamentada no século XX para lidar com alunos do século XXI, ou nas palavras de Gilson Schwartz: “Alunos do século XXI. Professores do século XX. Escolas do século XIX”. (2014, p.32)

Outro exemplo sobre o emprego do jogo de xadrez no espaço escolar se trata do filme de 2013, Jogada de Rei. Neste final, o xadrez foi o instrumento para desenvolvimento da capacidade de reflexão de jovens negros de uma escola americana de baixa renda, acontecimento verídico.

Por fim, o sentido equivocado do processo de transposição didática diz respeito à simplificação dos conceitos científicos em saberes escolares descontextualizados, como advertem Verhaeghe, Wolfs, Simon e Compère: "Os programas escolares, os modos de planejamento dos cursos contribuiriam assim para 'desnaturar' de algum modo os saberes científicos e deles oferecer uma visão enviesada aos alunos.” (2010, p.86) Continuando, eles comentaram: 
Como os saberes elaborados pela comunidade científica serão por fim comunicado aos alunos? Trata-se simplesmente, como às vezes se acredita, de um processo de simplificação dos saberes, com o intuito de torná-los mais acessíveis? Na verdade, o fenômeno é muito mais complexo. (2010, p. 86).

A mediação didática crítica envolve a elaboração de saberes não hegemônicos nas escolas. Muito embora o currículo escolar seja composto de um consenso em sua maioria eurocêntrico, em que acontecimentos fora do eixo do hemisfério norte são diminuídos ou ignorados, as aulas de sociologia podem convergir com outras disciplinas para desnaturalizar, estranhar, possibilitar autonomia e a formação da imaginação sociológica, finalidade primordial do ensino de Sociologia. Paulo Freire defende que utilizar a própria realidade dos alunos como dimensão sensível de análise e crítica do real possibilita a construção dessa imaginação sociológica:

Por que não aproveitar a experiência que têm os alunos de viver em áreas da cidade descuidadas pelo poder público para discutir, por exemplo, a poluição dos riachos e dos córregos e os baixos níveis de bem-estar das populações, os lixões e os riscos que oferecem à saúde das gentes. Por que não há lixões no coração dos bairros ricos e mesmo puramente remediados dos centros urbanos? (...) Por que não discutir com os alunos a realidade concreta a que se deva associar a disciplina cujo conteúdo se ensina, a realidade agressiva em que violência é a constante e a convivência das pessoas é muito maior com a morte do que com a vida? Por que não estabelecer uma "intimidade" entre os saberes curriculares fundamentais aos alunos e a experiência social que eles têm como indivíduos? (2011. p. 32)

Levando em conta essas observações de Freire, o elemento de passividade da concepção bancária que atravessa nosso imaginário educativo, limita e até rouba de crianças e jovens a oportunidade de assumirem que também possuem conhecimentos, criatividade e alegria em compartilhar estes saberes com o público. Ao trazer a experiência para o domínio deles, os estudantes já podem continuar e desenvolver uma independência compartilhada. Os saberes são legados construídos coletivamente, pois os grandes gênios da humanidade produziram a partir do conhecimento historicamente acumulado. A sociologia neste sentido observaria e desvendaria as facetas das relações de poder ocultas ou "naturalizadas" socialmente.

Se as artes de produzi-los como subordinados foram tão sofisticadas, será necessário desconstruir as concepções em que essas pedagogias de dominação se legitimaram. Será necessário rever com radicalidade até que ponto nos programas de educação popular, nas didáticas, nos processos de 
ensino/aprendizagem e nas avaliações e segregações/reprovações perduram formas de pensar e tratar setores populares, suas crianças e adolescentes como inferiores. Será necessário superar as formas de pensar os grupos populares como marginais que ainda predominam nas políticas públicas e, inclusive, em programas de educação popular. (ARROYO, 2013, p. 16).

Por fim, Geraldo Peçanha de Almeida sublinha a competência de um professor em transpor a forma dos saberes científicos para uma forma que não seja um assunto alienígena para os estudantes se configura mediante competência na experiência, como mostra a passagem a seguir:

Competência vem de técnica e técnica se aprende fazendo, Portanto, só se constrói um professor na prática diária de sala de aula. O professor segue construindo-se no espaço que ocupa, e essa construção se dá quando o espaço em que está inserido já é, ou será, mediante transformação que ele poderá implementar, um ambiente educativo. (ALMEIDA, 2007, p. 33)

A sociologia no ensino secundário pode desenvolver a curiosidade inquietante, uma imaginação sociológica. A desnaturalização e o estranhamento, a partir da vivência de professores e alunos. Constituir chaves de interesse e leitura com os alunos. Apreender a realidade social em seus aspectos contraditórios; apreender a questão do trabalho e como o ser humano transforma e é transformado pela natureza; apreender a questão dos valores e crenças subjetivas. No próximo tópico, as práticas educativas realizadas no âmbito do PIBID exemplificam a discussão teórica apresentada.

\section{Práticas educativas críticas no PIBID: brincando e pensando com autonomia}

As experiências vividas pela supervisora bem como bolsistas são essenciais para pensar como algumas as práticas educativas desenvolvidas nas aulas, como jogos didáticos e a semana da consciência negra foram relevantes para o desenvolvimento da autonomia e do pensamento crítico no espaço escolar da Sociologia.

A escola estadual na qual se desenvolve projeto é uma de referência, concorrida e central em termos de localização. Um público de diferentes cidades além de Niterói busca a escola, que atende inúmeros alunos de São Gonçalo, Itaboraí e Maricá. A escola funciona em três turnos (manhã, tarde e noite) e tem cerca de três mil estudantes, sendo uma das maiores da cidade. 
Parte dos professores leciona nesta escola há mais de vinte anos, tendo vivido vários momentos na instituição, bem como estabelecendo vínculos profundos. No tema por nós debatido, se tratando de uma escola tão grande e com tantos professores é difícil generalizar no que tange ao processo de transposição didática. Essa escola é conhecida por sua ênfase nos conteúdos e pelo seu alto índice de reprovação.

Sobre a disciplina de Sociologia, os professores atuam de maneira bastante isolada, como é realidade da rede estadual: o tempo dos professores na escola se resume aos tempos em sala. Não há reuniões de área, os debates entre os grupos de sociologia ocorrem via e-mail para discutir exigências da escola, como a dependência. Constitui uma exigência a entrega do planejamento formal. Alguns professores estabelecem diálogos, trocas por afinidades pessoais, muitas delas por relações construídas antes de serem professores na mesma escola.

O currículo que norteia os professores é o currículo mínimo, documento produzido pela secretária de educação que estabelece os conteúdos a serem trabalhados em cada bimestre de cada ano letivo.

A busca da professora e dos bolsistas nas aulas é desenvolver nos alunos, o pensamento crítico e reflexivo, promover debates, transmitir saberes e leituras sociais que lhes foram negadas. Assim também, estabelecer diálogos que tenham relação com a realidade dos alunos, tratar de questões para eles relevantes, trazer para sala de aula o que muitas vezes está excluído: a criatividade, a autonomia, a pesquisa.

A forma como trabalhar os conteúdos é sempre uma nova busca de como facilitar a compreensão, como ser prazeroso, como aliar aos interesses dos alunos e também como administrar o pouco tempo de aula (1 tempo de 50 minutos para as turmas de primeiro e segundo ano, e 2 tempos paras as turmas de terceiro ano). $\mathrm{O}$ material para uso nas aulas e o compartilhamento de experiências realizadas por outros professores da disciplina vêm se ampliando rapidamente nos últimos dois anos. Não obstante, ainda é incipiente se comparada a outras disciplinas, fato que se justifica no pouco tempo que a disciplina se faz obrigatória no currículo do ensino médio, desde 2009.

A experiência do PIBID permitiu uma grande experiência de construção coletiva, onde desde a elaboração das aulas, atividades, e até das avaliações, foram partilhados. Neste sentido as práticas educativas críticas são enfocadas a partir das narrativas sobre os jogos didáticos e da construção dos saberes relativos à Semana da Consciência Negra. 


\section{Narrativas sobre os Jogos Didáticos}

O emprego dos jogos buscou enfatizar o caráter construído e humano dos saberes ensinados, bem como sua problematização. Além disso, favoreceu um aprendizado de tipo construtivista, suscitando uma reflexão sobre a dimensão ética dos saberes. Duas experiências relacionadas aos jogos merecem ser lembradas.

A primeira ocorreu no quarto bimestre de 2014. Conjuntamente com outros professores da escola, foi desenvolvida a primeira mostra de cultura negra na escola. Os alunos estavam motivados para aprofundar essa temática, em decorrência da visita realizada ao Museu de Arte do Rio (MAR) para ver a exposição "Do cais do Valongo as favelas", Nosso intuito era debater assuntos muito ausentes do eurocentrismo do currículo escolar. Na minha disciplina, Sociologia, os grupos desenvolveram trabalhos sobre três temas:

$\checkmark$ Um outro olhar sobre a África;

$\checkmark$ Lideranças Negras da História do Brasil e

$\checkmark$ Religiões Afro Brasileiras.

Bons trabalhos foram desenvolvidos, ocorrendo uma participação fundamental dos estagiários do PIBID na orientação destes trabalhos.

Essa primeira experiência do jogo didático não foi planejada, sendo uma iniciativa dos bolsistas em criar algo motivador e diferente do quotidiano da sala de aula. O objetivo inicial foi utilizar o jogo didático como recurso de revisão e de aplicação da matéria dada no bimestre. Chegaram com o jogo pronto, denominando-o de bate-bola das questões. A proposta foi retomar o tema da consciência negra, levando em conta o conteúdo dado e apresentar outras informações e curiosidades suplementares àqueles trabalhados em torno da semana da cultura negra. $\mathrm{O}$ jogo consistia em elaborações de perguntas que seriam debatidas a partir das respostas.

Durante a execução do jogo, cada pergunta feita suscitava um debate com base nas respostas dos alunos, mesmo quando as respostas estavam incorretas. Verificamos que os alunos tinham uma inquietação para saber qual seria a resposta certa, o que gerou mais curiosidade e interesse por parte da turma. Um exemplo interessante dizia respeito à leitura por um aluno da pergunta sobre as três capitais da África do Sul. A turma sabia responder apenas duas capitais. A cada “chute" feito, uma discussão enriquecedora acontecia, pois no erro haviam pontos relacionados não só com a matéria do bimestre, mas com temas mais amplos.

No que se refere à transposição didática percebeu-se que a realização do jogo possibilitou uma articulação entre os conteúdos de maneira leve e bem humorada. Foi uma 
oportunidade de pegar um erro e transformá-lo em uma nova pergunta. Os alunos deram palpites. Alguns sabiam onde se situava a cidade que o colega havia exclamado e então percebemos que a interação entre bolsistas e alunos no jogo didático permitiu agregar mais conhecimento. Esta possibilidade não tinha sido planejada ou prevista anteriormente.

A segunda experiência com os jogos ocorreu no primeiro bimestre do ano de 2015 e denominou-se "jogada das afirmativas", aplicado para duas turmas de $3^{\circ}$ ano no final do primeiro Bimestre de 2015. Da mesma forma, o objetivo foi fazer uma revisão e aplicação da matéria dada em sala de aula. Dessa vez, a elaboração foi mais bem estruturada visando promover uma relação entre a matéria lecionada e questões relativas aos vestibulares. Esta dinâmica gerou motivação nos alunos, visto que muitos já estavam preparando-se para o vestibular. $\mathrm{O}$ conteúdo foi abordado com os temas sobre cultura, consumo e comunicação de massa. Afirmativas foram desenvolvidas e retiradas de provas de vestibulares, e os alunos organizados em grupo. Duas afirmativas eram projetadas nos slides e os grupos debatiam as afirmativas, a ponto de dizer se estavam certas ou erradas por meio dos cartões distribuídos pelos bolsistas que continham as opções.

A jogada das afirmativas feita em grupo possibilitou a discussão entre os alunos, estimulando a curiosidade. Ao responder que uma questão estava verdadeira ou falsa, os alunos ficavam apreensivos para saber qual dos grupos teria entregado o cartão certo. Quando havia uma das questões que era falsa e todos acertavam, perguntava-se direcionados a um grupo: grupo 1, onde está o erro? Assim, a dinâmica do jogo acontecia de forma participativa. Percebemos que além da participação, uma disputa saudável em um jogo didático possibilita que cada aluno aplique o conteúdo ensinado, superando a simples memorização decorrente de excessivas aulas expositivas.

O outro conjunto de práticas educativas críticas aplicado no ensino de Sociologia diz respeito ao processo de construção de saberes na Semana da Consciência Negra, relatada à continuação. Antes de adentrar nessa narrativa, é importante salientar que o processo envolve múltiplos contextos que se relacionam: a nível nacional tem-se movimentos crescentes na educação pública em prol da valorização das memórias, das histórias e dos costumes dos povos africanos; a nível local, na escola, uma busca por elaborar projetos que promovessem interdisciplinaridades de disciplinas e participação ativa dos estudantes. 


\section{Narrativas sobre os saberes da semana da Consciência Negra}

A semana de Consciência Negra, em sua segunda edição em 2015, contando com uma maior participação e colaboração estudantil, foi mais um ponto de resistência e de prática de saberes não legitimados numa instituição marcado pelo saber/ poder do consenso. A realização do evento coincidiu com o bimestre dedicado a discutir nas turmas do ensino médio sobre o que é violência e formas pelas quais esta se manifesta nas relações sociais. Nas salas de aula do ensino médio e em conjunto de bolsistas do PIBID se buscou formas de aproximar os temas com os saberes vividos pelos estudantes e ao mesmo tempo saindo do escopo de uma aula tradicional ao se dar a vez da performance aos alunos para desenvolverem pequenas encenações a respeito do que percebiam a respeito das violências presentes nos espaços de convívio: no trabalho, em casa, na escola, no próprio território.

Este tema e sua forma de abordagem, que se distanciou da mera apreensão passiva, em sala possibilitou o despertar de ideias em algumas turmas do $2^{\circ}$ e $3^{\circ}$ anos em desenvolver trabalhos dos mais diversos para a Semana de Consciência Negra, realizada em seu segundo ano consecutivo. Como de costume, esta Semana coincide com a semana do dia 20 de novembro, dia da Consciência Negra e de Zumbi dos Palmares. A data faz parte dos esforços dos grupos negros e quilombolas, como forma de protesto e também de memória. Protesto ao simbolismo do dia do fim da escravatura, tendo como figura máxima uma princesa branca assinando um papel com tinta, como se o marco fosse algo simplesmente dado de cima. E memória dos antepassados que não foram apenas humanos escravizados. Produziram costumes e crenças e todo um modo de ver o mundo que influenciou a sociedade brasileira, mesmo que as culturas africanas e quilombolas sejam desmerecidas nas políticas públicas.

No contexto dos temas sobre violência a aula sobre a exclusão socioespacial no Rio de Janeiro fomentou uma turma do $3^{\circ}$ ano a produzir uma espécie de seminário junto de esquetes, em que um grupo falava um pouco sobre os aspectos do desenvolvimento das favelas no Rio e nas violências que os moradores presenciam, sejam elas espacial, econômica, policial, etc. Adicionando também uma dose de criatividade ao imaginar e realizar encenações sobre o período. O evento contou com diversidade com exposições, rodas de música e de conversa, encenações teatrais, maquetes, vestimentas e alimentos tradicionais de povos de África, suas complexidades religiosas e a influência deste continente no Brasil.

Os bolsistas do PIBID, junto de outros professores, ajudaram com dicas de pesquisa, materiais para manufatura de peças ou esquemas de organização. O interessante está na 
formação de uma autonomia de alunos que pouco experimentaram disso em sua formação até então. Além dos laços de amizade, o trabalho em grupo ajuda com um desenvolvimento de uma ideia de coletividade compartilhada. $\mathrm{O}$ trabalho em equipe reforça para a identidade escolar que estudantes produzem manifestações artísticas, como as ilustrações a seguir:

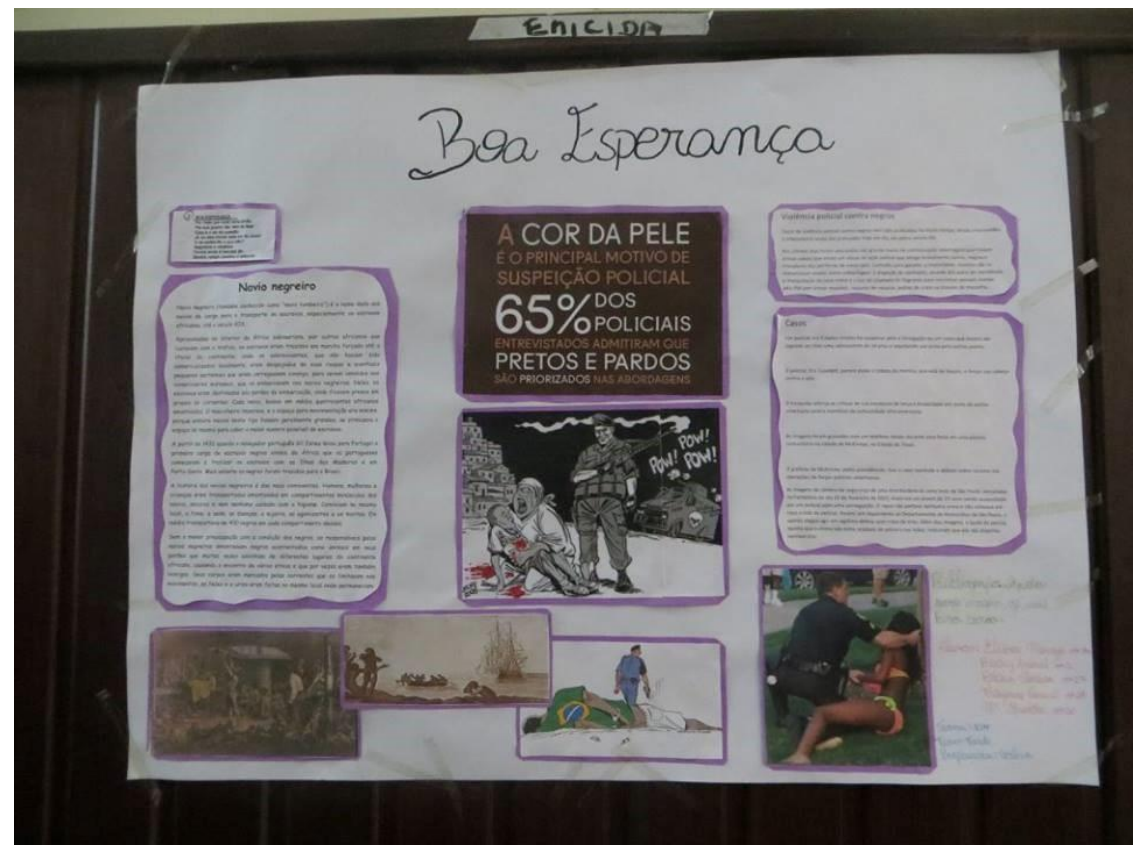

Figura 1 Cartaz pendurado no corredor. Referências a violência sobre o negro no Brasil. Muitos trabalhos assim, abordando diversos temas, se espalharam pelas paredes da escola.

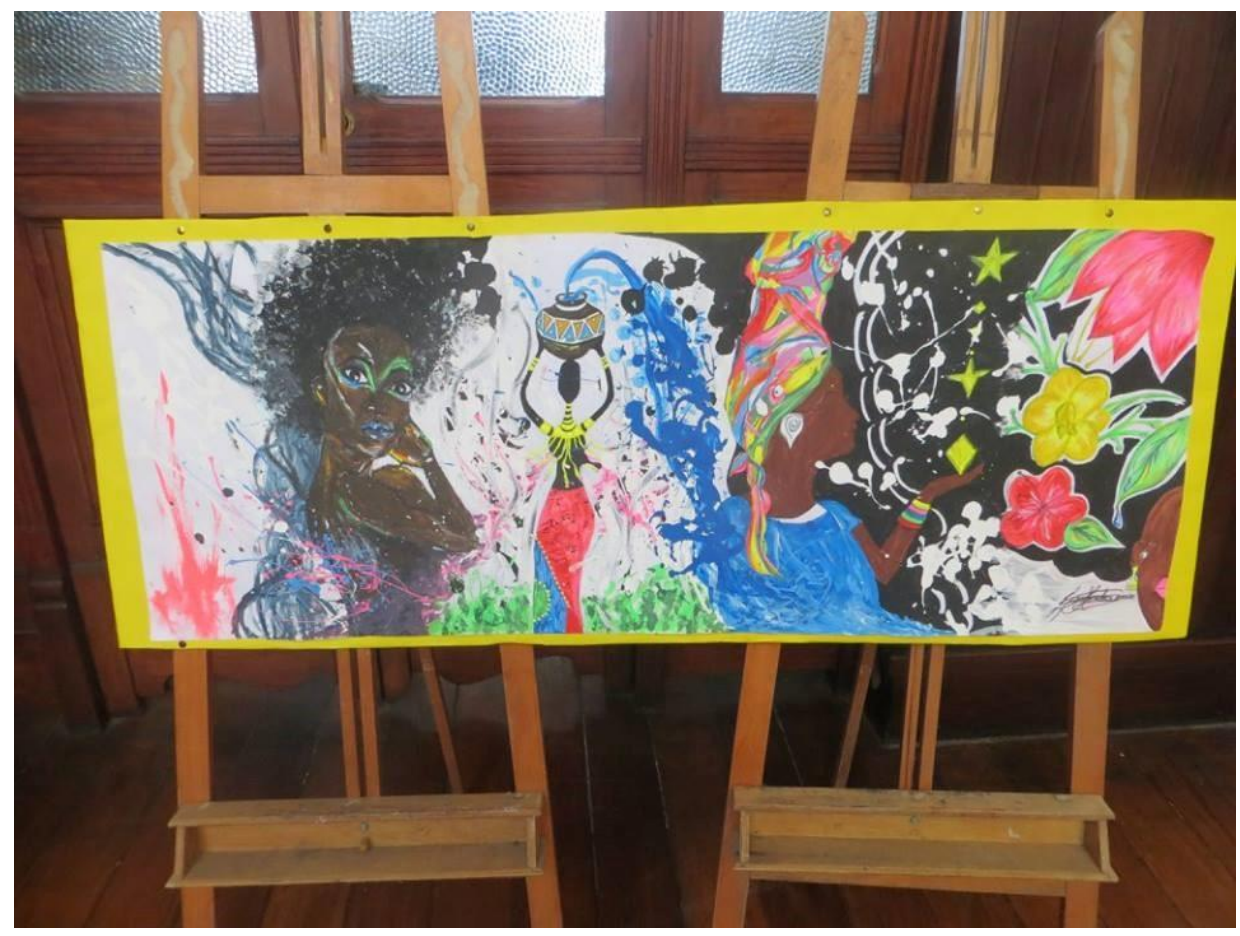

Figura 2: Pintura produzida por uma aluna. Elementos da cultura negra. 
Estas ilustrações demonstram as discussões que abarcam questões como autonomia, educação descolonial e contra-hegemonia. No senso comum a educação é concebida como algo unilateral: dos que possuem para os que nada possuem. Como a energia térmica em que o calor se dispersa das regiões mais quentes para as regiões mais frias. Se a educação é encarada desta maneira, é muito mais por questões de tradição e por manutenção de relações de poder do que algo natural. Tanto Freire quanto Arroyo (2013) encaram a formação de novas pedagogias a partir das relações dialéticas entre uma pedagogia central, dominante, e as outras formadas longe do poder legitimador.

Embora o currículo escolar seja composto de um consenso em sua maioria eurocêntrico, em que acontecimentos fora do eixo do hemisfério norte são diminuídos ou ignorados, as aulas de sociologia podem convergir com outras disciplinas e apresentar mediações quanto a professor e aluno para a formação de uma imaginação sociológica e, através da crítica da realidade, promover pensamentos contra-hegemônicos ${ }^{\mathrm{vi}}$.

Para Arroyo (2013) existem grupos historicamente excluídos dos mecanismos de poder e decisão no país: "trabalhadores, povos indígenas, negros, quilombolas, camponeses, favelados, ribeirinhos e seus filhos(as)". A estes grupos muitas vezes a concepção de cidadania ou mesmo de humanidade lhes é negada. Mas este processo também produz o seu contrário e é nisto que o autor considera um dos fenômenos mais desestabilizadores: tomarem acesso nas escolas e também reconhecerem que suas existências não são menores, que suas culturas produzem sistemas de trabalho, de educação tão importante quanto ao padrão hegemônico. Estes saberes despertam vivências diversas e assim pedagogias diversas. Por lhes serem negadas a condição de sujeitos, estes grupos produzem noções de "Outros sujeitos" que para o autor se refere aos grupos sociais que questionam políticas excludentes, exigem direitos, lutam por ações afirmativas de inclusão de grupos antes privados de visibilidade.

Segundo Arroyo, fundamentado no pensamento de Paulo Freire, os grupos sociais são compostos das pessoas que não se inserem ou são marginalizadas na lógica dominante do capital, ou, são sujeitadas na condição de subalternos. Estes indivíduos assumem a condição de sujeitos ao longo do século XX e início do XXI com suas formas de saber, de educar e de resistir, de propor outras experiências sociais e que por isso mesmo, outras pedagogias. Segundo Hobsbawm foi à tomada da consciência política destes grupos que tornaram o século XX o mais revolucionário da história. 
No choque de contradições presentes na sociedade capitalista, estes grupos que são produzidos e reproduzidos numa pedagogia subalternizante, produzem também formas contrárias ao estabelecido. Por terem sua condição de sujeitos negada, produzem outros sujeitos, novas práticas. O autor pensa em coletivos, o saber não é produzido isoladamente, é fruto de um legado de biografias, de memórias, de sujeitos que resistem e produzem formas culturais diversas. No ponto de vista de Arroyo,

O que há de mais significativo nesses coletivos em movimentos é ter tomado consciência política, tornando nosso tempo revolucionário. Repolitizam suas históricas resistências, "tantas lutas inglórias" - e se organizam em ações coletivas diversas, em movimentos sociais de libertação/emancipação dos padrões de poder, de trabalho, de apropriação/expropriação da terra, do solo, da riqueza, do conhecimento, das instituições do Estado. Nessas ações coletivas por libertação/emancipação se produzem Outros Sujeitos políticos e de políticas. Exigem reconhecimentos, constroem seus autorreconhecimentos. Pressionam o Estado por outro projeto de campo, de cidade, de sociedade. (2013, p. 15)

Considero estudantes das escolas públicas brasileiras como componentes de filhos e filhas destes grupos que historicamente lhe foram negados a condição de ser humano de maneira digna, respeitados por suas histórias e por cosmologias de saberes. Suas histórias de vida perpassam diferentes vivências que a educação tradicional não consegue lidar de outra maneira que não seja a da invisibilidade em favor de um saber já legítimo.

O saber considerado como o legitimado socialmente se desenvolveu historicamente na correlação de conflitos entre os grupos dominantes e os explorados. No Brasil, sua condição de colônia imprimiu na ideologia dominante a mentalidade da segregação espacial e intelectual do pensamento da elite com relação aos outros, os indígenas, os negros, os que não possuíam propriedades. No país dos bacharéis, a contradição se dá na necessidade do país investir em inovação e a de ter de agregar setores populacionais na lógica do capitalismo competitivo e, ao mesmo tempo, desejar permanecer na condição de imobilismo, do "cada um no seu lugar". A esta relação Lúcia Maria e Ronaldo Sant' Anna chamam de uma pedagogia da hegemonia.

São propostas como a Semana de Consciência Negra que trazem esses processos de resistências para uma instituição dominada por concepções pedagógicas que estão condicionadas pelo padrão saber/poder que reproduzem uma mentalidade colonizador/colonizado, submetendo estes outros sujeitos e sublimando suas outras práticas, outros saberes, outras culturas, outras pedagogias. 
Neste sentido, a sociologia pode tornar-se um instrumento para estimular projetos pedagógicos críticos e menos ortodoxos em sala de aula. Observando de um ponto de vista histórico, a disciplina construiu-se e foi, através de práticas diversas, abandonando a ideia de Auguste Comte de uma ciência para o progresso, para algo que temos mais atualmente, a de uma ciência que analisa os fenômenos sociais os mais diversos e que possibilita outro olhar sobre as coisas. Peter Berger denomina este outro olhar como "perspectiva sociológica".

Ao conversar com os alunos participantes dos eventos da Semana de Consciência Negra, conferirmos a importância da interdisciplinaridade, com os alunos aproveitando as aulas de geografia, história e as de língua estrangeira, com alguns destes professores estabelecendo contatos entre si para estimularem as turmas com os projetos apresentados. A questão sobre a favelização envolveu não só o que expus na aula expositiva sobre o processo desigual de formação do espaço da cidade do Rio de Janeiro desde Pereira Passos, o que este grupo de estudantes buscou incluir outras fontes e também o próprio componente da criatividade, como pode ser lido em alguns dos comentários sobre como foram realizados em cima da hora. Ora, é mais um sintoma de uma educação que deseduca na proatividade.

O estranhamento com que os estudantes encontraram ao tomarem uma atitude de serem ativos em algumas atividades se chocam contra a realidade escolar que não leva muito em conta o pensar reflexivo, imputando automaticamente o fracasso ao estudante.

\section{Considerações finais}

Neste artigo, nossas reflexões se voltaram para desconstrução de duas indagações centrais que norteiam a prática docente no ensino da Sociologia na educação básica. A primeira se referiu às possibilidades do ensino da Sociologia ultrapassar o método expositivo, empregando práticas educativas que fomentem o pensar autônomo dos alunos a partir de jogos e atividades de natureza interdisciplinar, como ocorreu na Semana da Consciência Negra. A segunda questão do artigo propôs repensar o espaço de aprendizagem do PIBID como um instrumento aglutinador de experiências, narrativas e saberes escolares críticos. Neste sentido, este artigo constitui uma ferramenta de defesa do PIBID em tempos de redução de investimento na educação pública de qualidade.

Vale lembrar que por mais que existam centros de ensino público que se destacam no ensino primário ou secundário, como o Colégio Pedro II no Estado do Rio de Janeiro ou os 
colégios dirigidos pelas próprias universidades públicas, são "ilhas de experiências" que não chegam à realidade concreta da maioria dos jovens no Brasil. Portanto, o PIBID merece ser preservado e ampliado para alcançar as escolas públicas brasileiras.

Por fim, o estranhamento e a desnaturalização a respeito das questões sociais das conjunturas brasileira e internacional finalidades prescritas nos Parâmetros Curriculares Nacionais (PCNs) relativas ao ensino da Sociologia são proficuamente enriquecidas na medida em que o docente adota práticas educativas críticas, como jogos didáticos e atividades interdisciplinares, com a parceria do PIBID.

\section{Referências}

ALMEIDA, Geraldo Peçanha de. Transposição didática. Por onde começar? São Paulo: Cortez, 2007.

ARROYO, Miguel G. Outros sujeitos. Outras Pedagogias. Petrópolis, RJ: Vozes, 2012.

BERGER, Peter. Perspectivas sociológicas: uma visão humanista. Petrópolis: Vozes, 1986.

CARVALHO, Lejeune Mato Grosso Xavier de (Organizador). Sociologia e Ensino em Debate. Experiências e Discussão de Sociologia no Ensino Médio. Ijuí: Editora Ijuí, 2004.

FREIRE, Paulo. Pedagogia do Oprimido. Rio de Janeiro: Paz e Terra, 1987.

Terra, 1996.

. Pedagogia da autonomia: saberes necessários à prática educativa. São Paulo: Paz e

OLIVEIRA, Luiz Fernandes de (Organizador). Ensino de Sociologia. Desafios teóricos e pedagógicos para as Ciências Sociais. Seropédica, RJ: Ed. da UFRRJ, 2013.

SCHWARTZ, Gilson. Brinco, logo aprendo. Educação, videogames e moralidades pósmodernas. São Paulo: Paulus, 2014.

VERHAEGHE, Jean-Claude et alli. Praticar a Epistemologia. Um manual de iniciação para professores e formadores. São Paulo: Edições Loyola, 2010. 
' Coordenadora de área do subprojeto de Ciências Sociais da UFF - Ciências; Professora adjunta do Departamento de Sociologia da UFF, Niterói; Coordenadora de Curso da Licenciatura em Ciências Sociais Niterói.

ii Supervisora do PIBID no Liceu Nilo Peçanha, licenciada em Ciências Sociais pela UFF e Mestre em Educação pela UFF.

iii Bolsista de Iniciação à Docência do PIBID no Liceu Nilo Peçanha, licenciando em Ciências Sociais da UFF Niterói.

iv O texto "A trajetória histórica da luta pela introdução da disciplina de Sociologia no Ensino Médio no Brasil" de Lejeune Carvalho esclarece o intervalo dessa disciplina no currículo, ora como obrigatória, ora como facultativa e ausente. IN: Sociologia e Ensino em Debate. Experiências e Discussão de Sociologia no Ensino Médio. Ijuí: Editora Ijuí, 2004.

${ }^{\mathrm{v}}$ Epistemologia diz respeito ao processo de produção e de transmissão do conhecimento dito científico, elaborado nas universidades e centros de pesquisa. Portanto, busca romper e superar as noções cotidianas e de senso comum. Assim também, procura demonstrar os caminhos metodológicos da descoberta e os argumentos discursivos para validação da pesquisa realizada.

vi A legitimação dos padrões de exploração e desigualdade. Este estado educador promove uma pedagogia da hegemonia, em que os indivíduos, através da ideologia e do consentimento, reproduzem as relações de classe e o imaginário dos grupos dominantes. Entretanto nada é absoluto e mesmo as relações produzem o seu contrário. Assim como Gramsci apreendeu a relação contraditória entre capital e trabalho e dos instrumentos do Estado para a formação consentimento (igreja, escola, meios de comunicação, associações, etc.), também sob uma "perspectiva radicalmente distinta", estas instituições também possuem em si a contradição na medida que guardam a possibilidade de serem objetos de disputa por grupos a margem do poder dominante de construírem contrahegemonias. Ver mais em Lúcia Neves e Ronaldo Sant'Anna (2005). 